Article

\title{
Distribution and Source Sites of Nonlinear Internal Waves Northeast of Hainan Island
}

\author{
Jianjun Liang ${ }^{1,2, *} \mathbb{D}$, Xiao-Ming $\mathrm{Li}^{1,2} \mathbb{C}$ and Kaiguo Fan ${ }^{3}$ \\ 1 Key Laboratory of Earth Observation of Hainan Province, Hainan Research Institute, Aerospace Information \\ Research Institute, Chinese Academy of Sciences, Sanya 572000, China; lixm@radi.ac.cn \\ 2 Key Laboratory of Digital Earth Science, Aerospace Information Research Institute, Chinese Academy of \\ Sciences, Beijing 100094, China \\ 3 School of Meteorology and Oceanography, National University of Defense Technology, \\ Changsha 410015, China; van.fkg@tom.com \\ * Correspondence: liangjj@radi.ac.cn
}

check for updates

Citation: Liang, J.; Li, X.-M.; Fan, K Distribution and Source Sites of Nonlinear Internal Waves Northeast of Hainan Island. J. Mar. Sci. Eng. 2022, 10, 55. https://doi.org/ $10.3390 /$ jmse10010055

Academic Editors: SungHyun Nam and Xueen Chen

Received: 22 November 2021 Accepted: 30 December 2021 Published: 4 January 2022

Publisher's Note: MDPI stays neutral with regard to jurisdictional claims in published maps and institutional affiliations.

Copyright: (C) 2022 by the authors. Licensee MDPI, Basel, Switzerland. This article is an open access article distributed under the terms and conditions of the Creative Commons Attribution (CC BY) license (https:// creativecommons.org/licenses/by/ $4.0 /)$.

\begin{abstract}
The distribution and source sites of nonlinear internal waves (NLIWs) northeast of Hainan Island were investigated using satellite observations and a wavefront propagation model. Satellite observations show two types of NLIWs (here referred to as type-S and type-D waves). The type-S waves are spaced at a semidiurnal tidal period and the type-D waves are spaced at a diurnal tidal period. The spatial distribution of the two types of NLIWs displays a sandwich structure in which the middle region is influenced by both types of NLIWs, and the northern and southern regions are governed by the type-S and type-D waves, respectively. Solving the wavefront model yields good agreement between simulated and observed wavefronts from the Luzon Strait to Hainan Island. We conclude that the NLIWs originate from the Luzon Strait.
\end{abstract}

Keywords: internal waves; South China Sea; Hainan Island

\section{Introduction}

Nonlinear internal waves (NLIWs) are often transformed from the propagation of nonlinear internal tides. They frequently occur in coastal oceans and marginal seas, and have strong effects on driving vertical mixing, scattering and ducting acoustic modes, and endangering underwater equipment and moving objects. Therefore, it is very important to know their source sites and to evaluate these effects.

The NLIWs in the northern South China Sea (SCS) have received a great deal of attention, particularly those from the Luzon Strait to Dongsha Atoll [1]. The Luzon Strait radiates strong semidiurnal and diurnal internal tides westward into the SCS due to the interactions of strong barotropic tidal currents [2] with the two shallow ridges: the HengChun ridge and the Lan-Yu ridge [3]. In the deep basin, the semidiurnal internal tides can steepen to form NLIWs under the influence of nonhydrostatic and rotational dispersion; by contrast, the rotation significantly inhibits the steepening of diurnal internal tides [4]. Then, the NLIWs diffract and refract around Dongsha Atoll [5], dissipating most of their energy [6,7]. Continuing with northwestward propagation, the NLIWs may experience a polarity conversion under the condition that the pycnocline is below the mid-depth [8].

Satellite observations show that NLIWs also occur frequently on the continental slope-shelf northeast of Hainan Island $[9,10]$, as shown by the black rectangle in Figure 1. Moreover, field measurements show that the largest NLIWs in the region can reach an amplitude of $45 \mathrm{~m}$ at a water depth of $117 \mathrm{~m} \mathrm{[11],} \mathrm{making} \mathrm{them} \mathrm{among} \mathrm{the} \mathrm{strongest} \mathrm{waves}$ observed on global continental shelves [12]. 


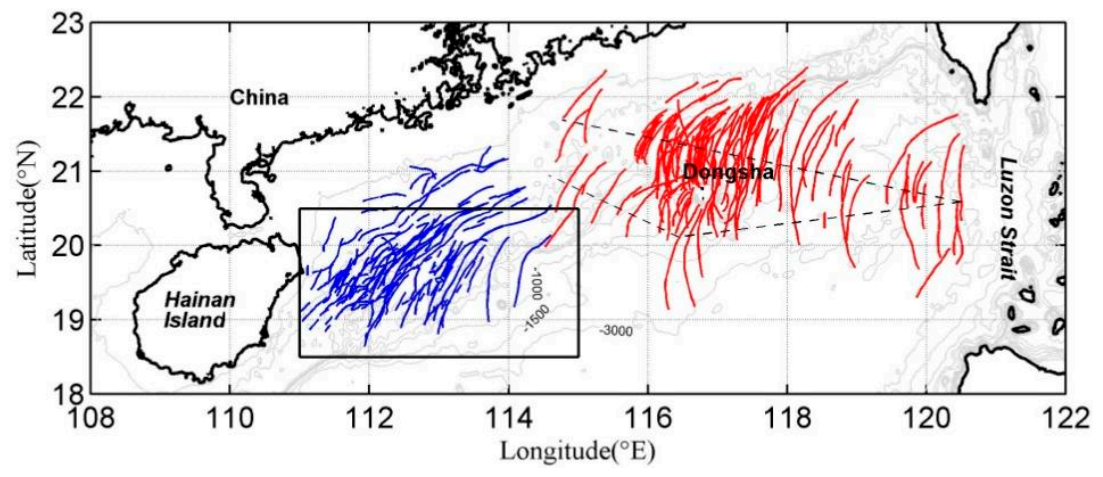

Figure 1. Satellite observations of NLIWs. The black rectangle shows the study region. The red and black lines represent the satellite-observed wavefronts of NLIWs. The red lines are those provided by Zhao et al. [13], and the blue lines are extracted from the collected satellite images in this study. The black dashed lines show the commonly recognized propagation path of NLIWs originating from the Luzon Strait.

By calculating barotropic tidal forcing and analyzing three Envisat Advanced Synthetic Aperture Radar (ASAR) images, Li et al. [14] suggests that the SAR-observed NLIWs northeast of Hainan Island originate from the Luzon Strait. A common view of the NLIWs originating from the Luzon Strait is that they can transit through the deep basin and diffract around Dongsha Atoll, as shown by the black dashed lines in Figure $1[5,15]$. However, whether these NLIWs can directly arrive at the area northeast of Hainan Island remains unclear. In contrast, $\mathrm{Xu}$ et al. [16] found that the field-observed NLIWs are generated by nonlinear transformation of diurnal internal tides and they suggest that the diurnal internal tides arise from tide-topography interactions at the local continental shelf-break, distinct from the result of Li et al. [14]. The two above-mentioned opposing opinions on the NLIWs northeast of Hainan Island warrant further investigations into their source sites.

Moreover, apart from the NLIWs separated by a diurnal tidal period as observed by $\mathrm{Xu}$ et al. [16], we also found NLIWs separated by a semidiurnal tidal period by analyzing the satellite data. Hence, there are two types of NLIWs northeast of Hainan Island, referred to as type-S ( $\mathrm{S}$ denotes semidiurnal) and type-D (D denotes diurnal) waves. A meaningful question then arises of whether there is a general distribution law for these two types of NLIWs. Here, we combine satellite observations and a wavefront propagation model to clarify the distribution and source sites of NLIWs northeast of Hainan Island.

\section{Materials and Methods}

\subsection{Satellite Data}

We collected 22 Envisat ASAR images in the three years 2005, 2011, and 2012 to show the spatial distribution of NLIWs. All the SAR images are preprocessed by radiometric calibration, Lee filtering, and geolocation. The leading wave in a NLIWs packet is depicted as a blue line in Figure 1. The SAR observations clearly show complete type-S waves and only show some segments of type-D waves. Hence, one Moderate Resolution Imaging Spectrometer (MODIS) image acquired on 10 September 2005 was used to clearly show a pair of complete type-D waves.

\subsection{A Wavefront Propagation Model}

We used the Eikonal equation [17] to simulate the propagation path of NLIWs because the waves always appear as long stripes (referred to as wavefronts) in satellite images. The equation is:

$$
T_{x}^{2}+T_{y}^{2}=1 / c(x, y)^{2},
$$

where $T$ is the time for a wave propagating from an origin to a location $(x, y)$ and $c(x, y)$ is the local wave speed. Here, we used the statistical propagation speed model given by 
Jackson [18] to calculate $c(x, y)$. The model relates the wave speed in the northern SCS to local water depth $H(x, y)$ in the following manner:

$$
c(x, y)=2.971 \times \sqrt{\tanh (0.003+H(x, y) / 1390.758)} .
$$

Thus, the propagation path of NLIWs can be determined when the origin is known. According to the simulated and measured baroclinic energy flux in the Luzon Strait, we specified the origin near the Batan Islands [19]. Equation (1) was solved by the fast marching method [20].

\section{Results}

\subsection{Distribution of the Two Types of NLIWs}

An Enivsat ASAR image acquired on 8 June 2011 presenting typical type-S waves is shown in Figure 2. There are four NLIWs with long wavefronts labeled S1, S2, S3, and S4. The separation distances between S1, S2, S3, and S4 are 92, 59, and $48 \mathrm{~km}$, respectively. According to Equation (2), the decrease in the separation distance is caused by a decrease in wave speed from $2.34 \mathrm{~m} / \mathrm{s}$ at $1000 \mathrm{~m}$ through $1.75 \mathrm{~m} / \mathrm{s}$ at $500 \mathrm{~m}$ to $0.81 \mathrm{~m} / \mathrm{s}$ at $100 \mathrm{~m}$. Comparing the four NLIWs with simulated wavefronts, we found the interval between them is approximately a semidiurnal tidal period. Because it takes $82 \mathrm{~h}$ for a wave to propagate from the Luzon Strait to the position of S1, we examined the tidal forcing during 3-5 June in the Luzon Strait. The TPXO7.2 tidal model [21] predicts the semidiurnal barotropic tides are near the semidiurnal spring tide, indicating the strong generation of semidiurnal internal tides in the Luzon Strait. Thus, the four NLIWs are probably generated by the nonlinear transformation of four successive semidiurnal internal tides, leading to a semidiurnal tidal period interval. In addition, there is a NLIWs with a shorter wavefront, labeled SA1, and the wavefront breaks up into two arms near the Shenhu Ansha Shoal, located at approximately $19.5^{\circ} \mathrm{N}, 112.9^{\circ} \mathrm{E}$. The SA1 was generated by the diffraction of S3 at a time earlier than the SAR acquisition time. This diffraction process is the same as the well-known one near Dongsha Atoll [14].

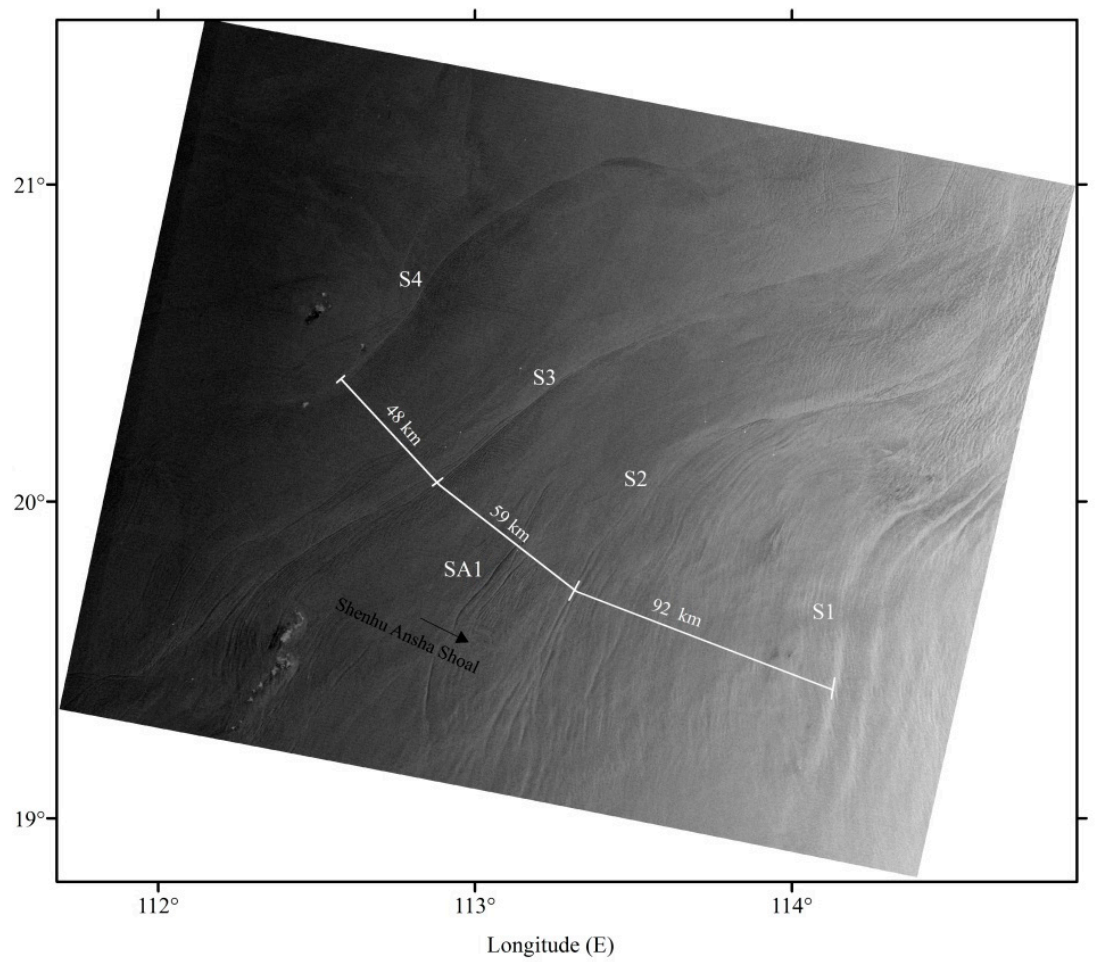

Figure 2. An Envisat ASAR image acquired at 02:30:04 UTC on 8 June 2011. 
A representative satellite observation of the type-D waves by MODIS is shown in Figure 3. There are two wave packets labeled D1 and D2. The distance between D1 and D2 is $97 \mathrm{~km}$, and the associated mean wave speed is $1.03 \mathrm{~m} / \mathrm{s}$. A comparison between the two wave packets and simulated wavefronts clearly reveals that the interval between them (approximately $26 \mathrm{~h}$ ) is close to a diurnal tidal period. In addition, the satellite observation agrees with the field measurements, which also show that the NLIWs are separated by a diurnal tidal period [16]. However, the TPXO7.2 tidal model predicts the barotropic diurnal tides during 5-7 September in the Luzon Strait are near diurnal neap tide (close to zero on 7 September), suggesting weak generation of diurnal internal tides. By comparison, the barotropic semidiurnal tides are still near semidiurnal spring tide, resulting in strong generation of semidiurnal internal tides. The weak generation of diurnal internal tides and strong generation of semidiurnal internal tides appear to contradict the fact that D1 and D2 are separated by a diurnal tidal period. A hypothesis is that the parametric subharmonic instability of semidiurnal internal tides may lead to the generation of a near-diurnal internal wave on the continental slope [22] or in the deep basin [23] in the northern SCS, which accounts for the diurnal tidal period interval between D1 and D2.

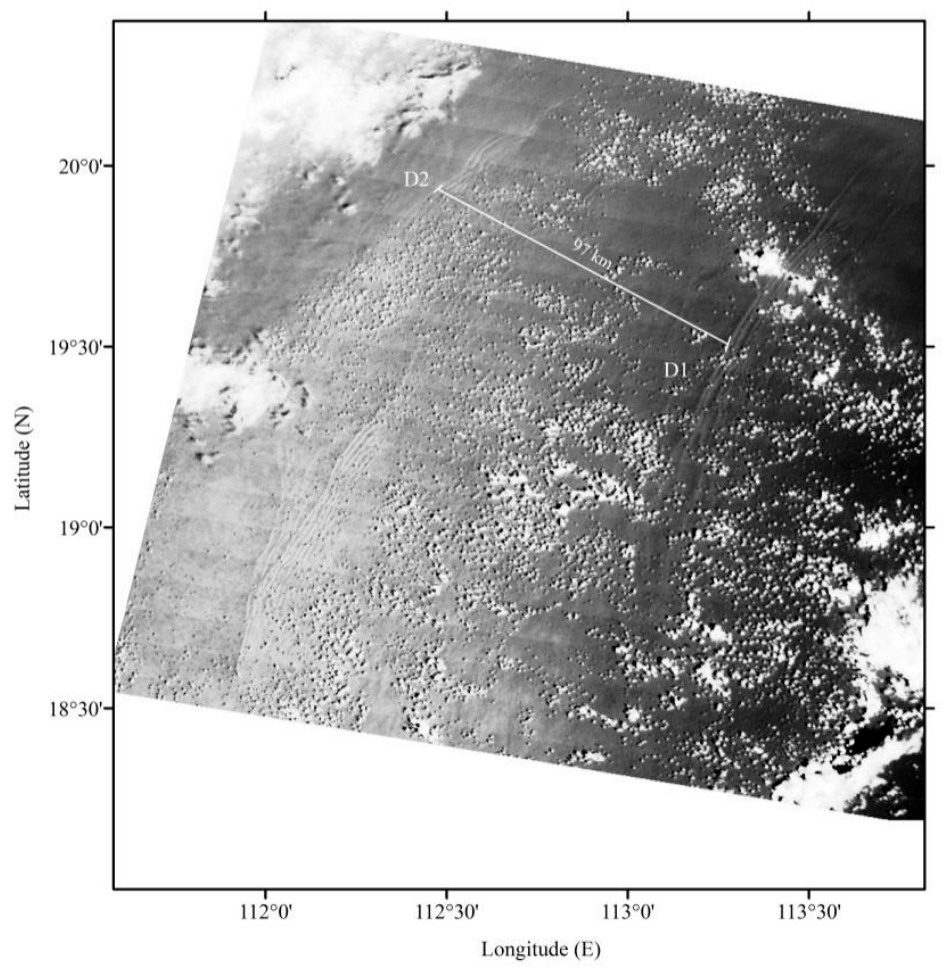

Figure 3. A MODIS image acquired at 03:20:00 UTC on 10 September 2005.

As shown in Figure 1, the wave patterns illustrated by the blue lines are very complicated. Despite the complication, we found a general distribution law for the two types of NLIWs by comparing other satellite observations with the two cases shown in Figures 2 and 3. Basically, the wave processes observed in other satellite images can be explained as variations in the two cases. This argument is supported by the inherent nature of the tidal origin for the NLIWs. Thus, we plotted all the type-S and type-D waves as blue and magenta lines, respectively, in Figure 4. The boundaries separating the two types of NLIWs were drawn by visual inspection of their spatial distribution. As can be seen, the region labeled RS ( $R$ denotes region) is dominated by type-S waves, the region labeled RSD is influenced by both types of NLIWs, and the region labeled RD is dominated by type-D waves. Note that the region RD contains the mooring position of $\mathrm{Xu}$ et al. [16], which sees remarkable NLIWs separated by a diurnal tidal period. 


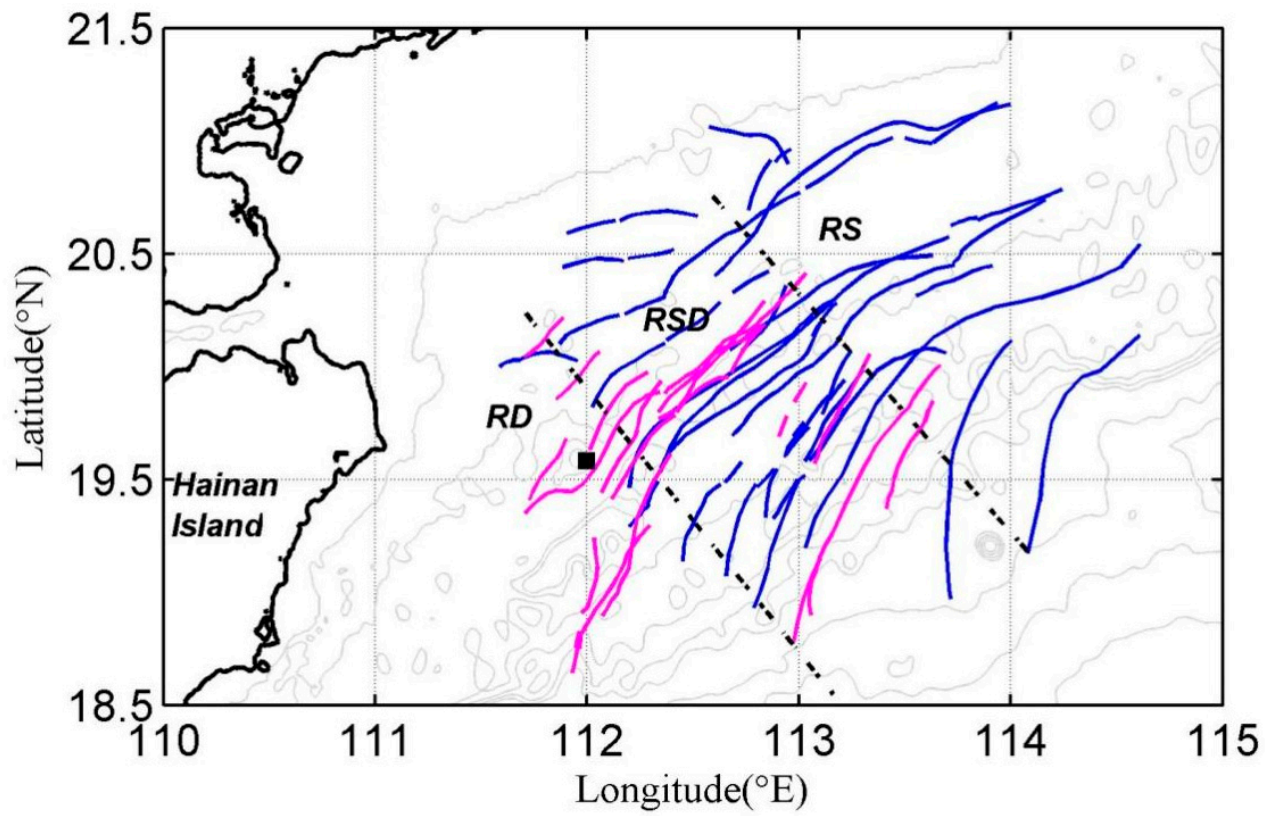

Figure 4. A general distribution pattern of the NLIWs. The blue lines represent type-S waves and the magenta lines represent type-D waves. The two dashed lines depict the boundaries for the distribution of the two types of NLIWs. The filled black square denotes the mooring position of $\mathrm{Xu}$ et al. [16].

\subsection{Source Sites of the Two Types of NLIWs}

Following the distinction of the two types of NLIWs, we next examine their source sites. Solving Equation (1) obtains the simulated wave propagation from the Luzon Strait to Hainan Island (black lines in Figure 5). The simulated wavefronts agree with all the observed wavefronts, including those from the deep basin of the SCS through Dongsha Atoll and the continental slope-shelf to the coastal region of Hainan Island. In particular, the simulated wavefronts agree surprisingly well with the easternmost wavefront and northern portions of other wavefronts in Figure 6a and the two wavefronts in Figure 6b. The agreement shown in Figures 5 and 6 indicates that the source site of NLIWs northeast of Hainan Island is in the Luzon Strait. Further evidence that supports this argument is that both the easternmost wavefronts in Figure 6a,b appear on the continental slope and run across the water depths from 200 to $1000 \mathrm{~m}$, suggesting they have a remote source site.

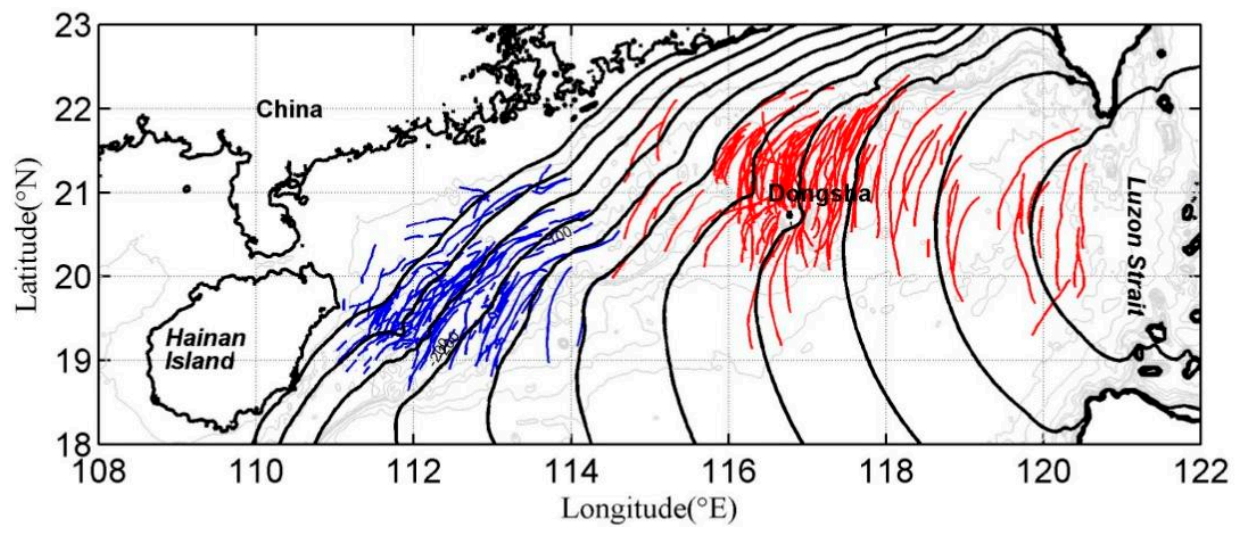

Figure 5. Distribution of simulated wavefronts. The black lines are drawn every $12 \mathrm{~h}$. 

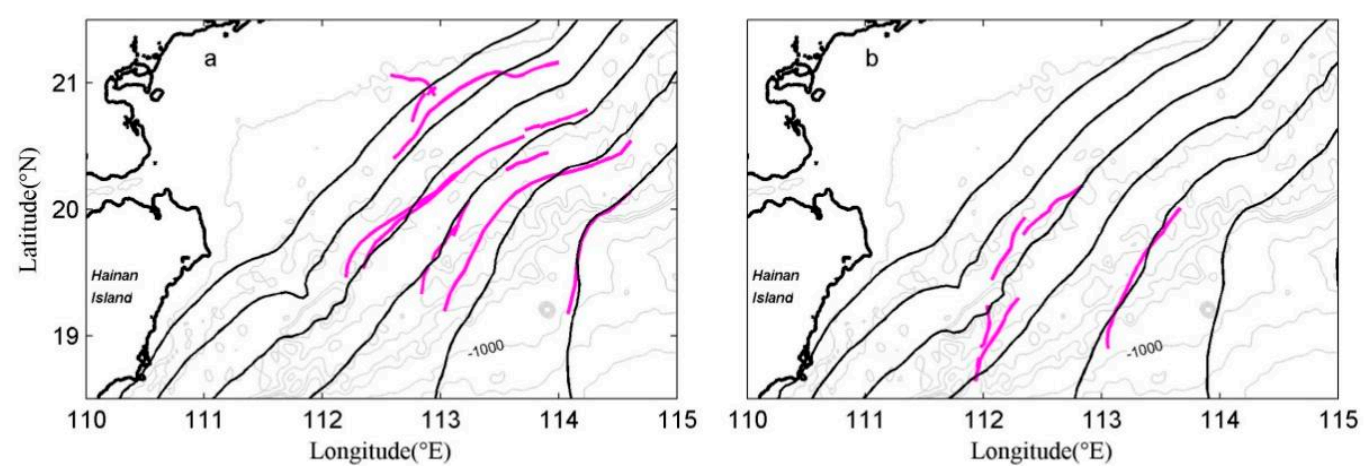

Figure 6. Specific comparisons for simulated and observed wavefronts for the type-S waves (a) and type-D waves (b). The magenta lines in $(\mathbf{a}, \mathbf{b})$ are extracted from Figures 2 and 3 , respectively. The black lines are drawn every $12 \mathrm{~h}$.

\section{Discussion and Conclusions}

Li et al. [14] found that the NLIWs also originate from the Luzon strait by analyzing three Envisat ASAR images and the phase-locked relation between the NLIWs and the tidal forcing in the Luzon Strait. However, they did not further discriminate the NLIWs separated by a semidiurnal and diurnal tidal period. Li et al. [14] labeled four NLIWs S1, S2, S3, and S4 in the SAR image taken on 6 November 2005 (Figure 7). They noted that S1 and S3 are generated with a $36 \mathrm{~h}$ lag in the Luzon Strait, implying that they are generated within two lunar days. However, we found that $\mathrm{S} 1$ and $\mathrm{S} 3$ have a $12 \mathrm{~h}$ lag by comparing the observed and simulated wavefronts. The generation time lag of $36 \mathrm{~h}$ may not be reduced to $12 \mathrm{~h}$ when they propagate from the Luzon Strait to the SAR observation site. In addition, analysis of the barotropic tidal forcing during 1-3 November in the Luzon Strait reveals that semidiurnal tides are near semidiurnal spring tide, and diurnal tides are in the transition period from diurnal neap to spring tide (Figure 8). The tidal forcing implies the generation of strong semidiurnal internal tides and somewhat weak diurnal internal tides. Thus, a more reasonable explanation is that $\mathrm{S} 1$ and $\mathrm{S} 3$ are generated by successive semidiurnal internal tides within one lunar day (Figure 8). Given that the crest length of S2 wavefront is significantly shorter than those of S1 and S3, and S2 is more southerly, we infer that S2 is generated by the nonlinear transformation of the diurnal internal tide formed within the same lunar day as the semidiurnal internal tides, according to Figures 4 and 8.

Although the wavefront propagation model developed by Jackson [18] is sufficiently robust to simulate the propagation of wavefronts from the Luzon Strait to continental slopes and Dongsha Atoll [24], it has relatively large uncertainties in predicting the propagation of wavefronts near shelf-break regions, particularly as revealed by the second easternmost wavefront in Figure 6a. This mismatch is caused by the effects of wave amplitudes and mesoscale currents on the propagation speed, which are not well accounted for in the statistical propagation model proposed by Jackson [18]. A more accurate propagation speed model for shelf-break regions needs to be developed.

As revealed by Figures 2, 3 and 7, the easternmost NLIWs will undergo complicated evolution when they propagate onshore, such as wave fission, polarity transformation, refraction, and dissipation, leading to more dense wavefronts on the middle continental shelf. The wave evolution is probably caused by the highly variable continental slope-shelf topography and mesoscale eddies and fronts. How and where these processes primarily affect the vertical mixing, local ecosystem, and sediment transport remains unknown. These questions may need further investigations because the NLIWs are among the largest waves on the global continental shelves.

The confusion regarding the source sites of NLIWs northeast of Hainan Island has persisted for nearly ten years. Here, we combine satellite observations and a wavefront propagation model to clarify the two types of NLIWs, provide a general law for their distribution, and demonstrate that these waves originate from the Luzon Strait. 


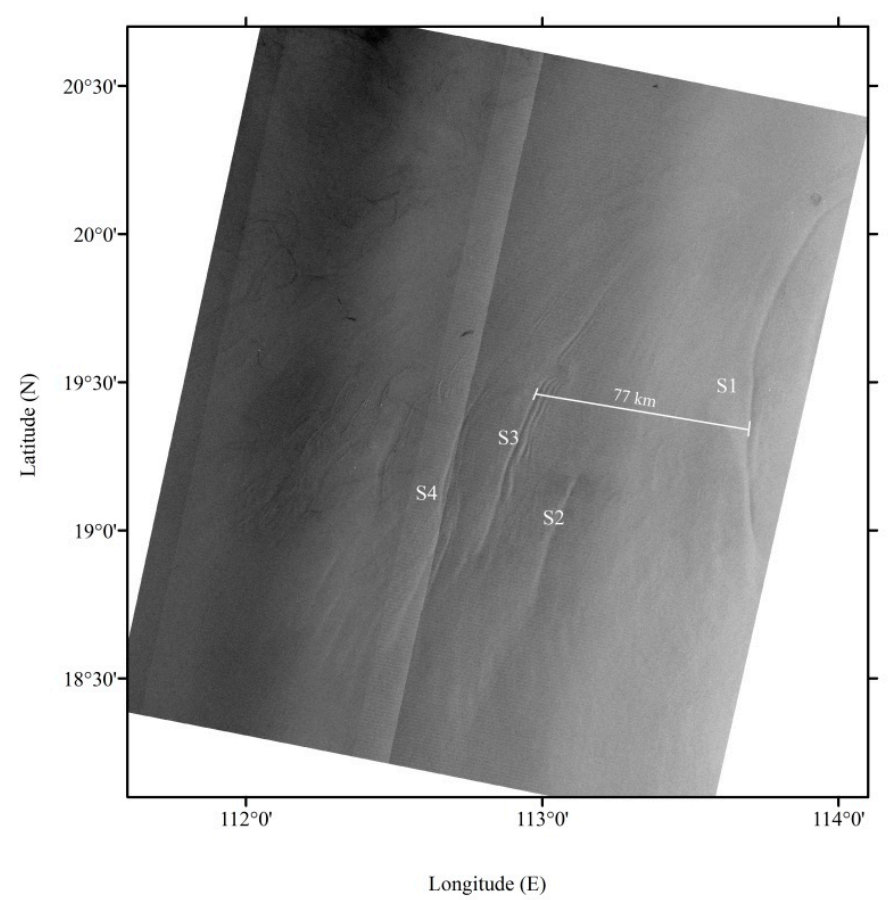

Figure 7. An Envisat ASAR image acquired at 02:28:22 UTC on 6 November 2005.

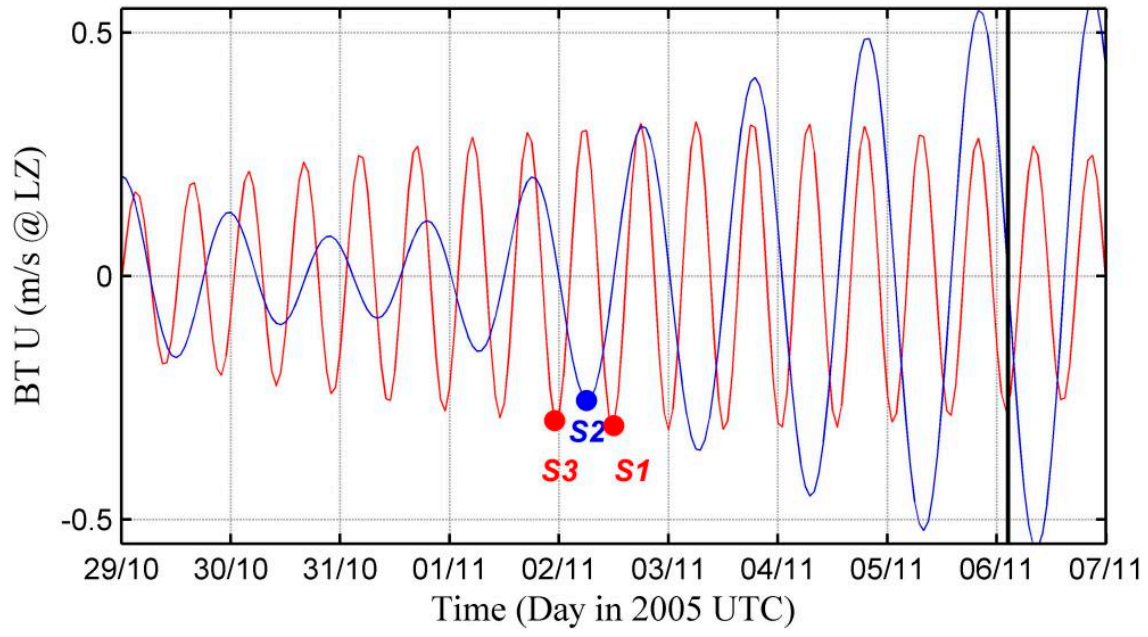

Figure 8. Semidiurnal (red) and diurnal (blue) components of zonal tidal current predictions (TPXO 7.2) in the Luzon Strait. The dots S1, S2, and S3 indicate the westward tidal current peaks corresponding to the S1, S2, and S3 NLIWs in Figure 7, respectively. The thick black line indicates the SAR imaging time in Figure 7.

Author Contributions: Conceptualization, J.L. and X.-M.L.; Data curation, J.L.; Formal analysis, J.L.; Funding acquisition, J.L.; Investigation, J.L.; Methodology, J.L.; Project administration, J.L.; Resources, J.L.; Software, J.L.; Supervision, J.L.; Validation, J.L., X.-M.L. and K.F.; Visualization, J.L. and X.-M.L.; Writing—original draft, J.L.; Writing—review \& editing, J.L., X.-M.L. and K.F. All authors have read and agreed to the published version of the manuscript.

Funding: This research was funded by Hainan Provincial Natural Science Foundation of China, grant number 420MS073.

Institutional Review Board Statement: Not applicable.

Informed Consent Statement: Not applicable. 
Data Availability Statement: The SAR images were downloaded from http:/ / ids.ceode.ac.cn/Index. aspx, accessed on 21 November 2021, and the MODIS image was downloaded from https:/ /ladsweb. modaps.eosdis.nasa.gov, accessed on 21 November 2021. The red lines in Figure 1 were downloaded from https:/ / figshare.com/authors/Zhongxiang_Zhao/5776886, accessed on 21 November 2021.

Acknowledgments: We thank the Open Spatial Data Sharing Project launched by the Aerospace Information Research Institute for providing the SAR data and NASA's LAADS Web for providing the MODIS image.

Conflicts of Interest: The authors declare no conflict of interest.

\section{References}

1. Guo, C.C.; Chen, X.E. A review of internal solitary wave dynamics in the northern South China Sea. Prog. Oceanogr. 2014, 121, 7-23. [CrossRef]

2. Ye, A.L.; Robinson, I.S. Tidal dynamics in the South China Sea. Geophys. J. R. Astr. Soc. 1983, 72, 691-707. [CrossRef]

3. Zhao, Z. Internal tide radiation from the Luzon Strait. J. Geophys. Res. 2014, 119, 5434-5448. [CrossRef]

4. Helfrich, K.R.; Grimshaw, R.H.J. Nonlinear disintegration of the internal tide. J. Phys. Oceanogr. 2008, 38, 686-701. [CrossRef]

5. Jia, T.; Liang, J.J.; Li, X.-M.; Sha, J. SAR observation and numerical simulation of internal solitary wave refraction and reconnection behind the Dongsha Atoll. J. Geophys. Res. Oceans 2018, 123, 74-89. [CrossRef]

6. Chang, M.-H.; Lien, R.-C.; Tang, T.Y.; D’Asaro, E.A.; Yang, Y.J. Energy flux of nonlinear internal waves in northern South China Sea. Geophys. Res. Lett. 2006, 33. [CrossRef]

7. Lien, R.-C.; D'Asaro, E.A.; Henyey, F.; Chang, M.-H.; Tang, T.-Y.; Yang, Y.-J. Trapped Core Formation within a Shoaling Nonlinear Internal Wave. J. Phys. Oceanogr. 2012, 42, 511-525. [CrossRef]

8. Liu, A.K.; Chang, Y.S.; Hsu, M.K.; Liang, N.K. Evolution of nonlinear internal waves in the East and South China Seas. J. Geophys. Res. 1998, 103, 7995-8008. [CrossRef]

9. Liu, A.K.; Hsu, M.K. Internal wave study in the South China Sea using Synthetic Aperture Radar (SAR). Int. J. Remote Sens. 2004, 25, 1261-1264. [CrossRef]

10. Alpers, W.; He, M.-X.; Zeng, K.; Guo, L.-F.; Li, X.-M. The distribution of internal waves in the China Seas studied by multi-sensor satellite images. In Proceedings of the 2005 Dragon Symposium, Santorini, Greece, 27 June 27-1 July 2005.

11. Xu, Z.H.; Yin, B.S.; Hou, Y.J. Highly nonlinear internal solitary waves over the continental shelf of the northwestern South China Sea. Chin. J. Ocean. Limnol. 2010, 28, 1049-1054. [CrossRef]

12. Alford, M.H.; Mickett, J.B.; Zhang, S.; MacCready, P.; Zhao, Z.; Newton, J. Internal waves on the Washington continental shelf. Oceanography 2012, 25, 66-79. [CrossRef]

13. Zhao, Z.; Klemas, V.; Zheng, Q.; Yan, X.-H. Remote sensing evidence for baroclinic tide origin of internal solitary waves in the northeastern South China Sea. Geophys. Res. Lett. 2004, 31. [CrossRef]

14. Li, X.F.; Zhao, Z.X.; Pichel, W.G. Internal solitary waves in the northwestern South China Sea inferred from satellite images. Geophys. Res. Lett. 2008, 35. [CrossRef]

15. Li, Q.; Farmer, D.M. The generation and evolution of nonlinear internal waves in the deep basin of the South China Sea. J. Phys. Oceanogr. 2011, 41, 1345-1363. [CrossRef]

16. Xu, Z.H.; Yin, B.S.; Hou, Y.J.; Fan, Z.S.; Liu, A.K. A study of internal solitary waves observed on the continental shelf in the northwestern South China Sea. Acta Oceanol. Sin. 2010, 29, 18-25. [CrossRef]

17. Whitham, G.B. Linear and Nonlinear Waves; John Wiley \& Sons, Inc.: Hoboken, NJ, USA, 1999.

18. Jackson, C.R. An empirical model for estimating the geographic location of nonlinear internal solitary waves. J. Atmos. Ocean. Technol. 2009, 26, 2243-2255. [CrossRef]

19. Alford, M.H.; MacKinnon, J.A.; Nash, J.D.; Simmons, H.; Pickering, A.; Klymak, J.M.; Pinkel, R.; Sun, O.; Rainville, L.; Musgrave, R.; et al. Energy flux and dissipation in Luzon strait: Two tales of two ridges. J. Phys. Oceanogr. 2011, 41, 2211-2222. [CrossRef]

20. Sethian, J.A. Level Set Methods and Fast Marching Methods; Cambridge University Press: Cambridge, UK, 1999.

21. Egbert, G.D.; Erofeeva, S.Y. Efficient Inverse Modeling of Barotropic Ocean Tides. J. Atmos. Ocean. Technol. 2002, 19, 183-204. [CrossRef]

22. Xie, X.-H.; Chen, G.-Y.; Shang, X.-D.; Fang, W.-D. Evolution of the semidiurnal (M2) internal tide on the continental slope of the northern South China Sea. Geophys. Res. Lett. 2008, 35. [CrossRef]

23. Liu, Q.; Shang, X.; Xie, X. Observations of semidiurnal M2 internal tidal parametric subharmonic instability in the northeastern South China Sea. J. Ocean. Limnol. 2021, 39, 56-63. [CrossRef]

24. Li, X.F.; Jackson, C.R.; Pichel, W.G. Internal solitary wave refraction at Dongsha Atoll, South China Sea. Geophys. Res. Lett. 2013, 40, 3128-3132. [CrossRef] 